\title{
Promoting Self-Management Behaviors In Adolescents With Type 1 Diabetes, Using Digital Storytelling: A Randomized Controlled Trial
}

\author{
Nahid Zarifsanaiey ( $\square$ nzarifsanaee@gmail.com ) \\ Shiraz university of medical sciences \\ Masoomeh Otrodi Shirazi \\ Shiraz university of medical sciences \\ Manoosh Mehrabi \\ Shiraz university of medical sciences \\ Zahra Bagheri \\ Shiraz university of medical sciences
}

\section{Research Article}

Keywords: Type 1 diabetes, Adolescents, training, Digital storytelling, Glycosylated hemoglobin, Self-management

Posted Date: July 1st, 2021

DOI: https://doi.org/10.21203/rs.3.rs-587938/v1

License: (c) (1) This work is licensed under a Creative Commons Attribution 4.0 International License. Read Full License

Version of Record: A version of this preprint was published at BMC Endocrine Disorders on March 22nd, 2022. See the published version at https://doi.org/10.1186/s12902-022-00988-7. 


\section{Abstract}

Background: This study aimed to assess the effects of digital storytelling on the self-management behavior of adolescents with type 1 diabetes (TID).

Methods: In this randomized controlled clinical trial, 60 adolescents with TID were randomly allocated into two parallel groups: intervention (training with digital storytelling method, $n=33$ ) or control (training with a conventional method, $n=33$ ). The primary outcome was the assessment of the Self-Management behavior of adolescents with TID (SMOD-A), at baseline and three months after the intervention.

Results: The results revealed that digital storytelling can lead to significant improvement in self-management behaviors amongst the adolescents with TID $(P=0.005)$, while in the control group no significant changes were observed $(P>0.05)$. The results also showed that the level of collaboration with parent's dimension scores had a significant reverse relationship with the adolescent age after digital storytelling $(p=0.048)$. With respect to HbA1c levels, significant changes were not observed in any of the groups $(P>0.05)$.

Conclusions: Digital storytelling is practicable and a potentially beneficial training modality for adolescents with TID.

Trial registration: This trial was respectively registered.

ClinicalTrials.gov Identifier: IRCT20191220045828N1.

Date of registration: Oct 29. 2020

\section{(https://clinicaltrials.gov/ct2/show/NCT04608058?term=zarifsanaiey\&draw=2\&rank=1)}

\section{Background}

Type 1 diabetes (TID) is one of the most prevalent endocrine gland diseases in adolescents, affecting almost one out of every 300 to 500 youngsters. Its incidence amongst adolescents is on the rise globally (1). Diabetes is a chronic condition that requires special selfmanagement behaviors throughout life. Self-management can lead to improved patients' general health, active engagement in the care process, improved quality of life, and ultimately, reduction in chronic complications (2). Studies revealed that self-management can be beneficial to adolescents in order to advance their knowledge and skills, leading to appropriate changes in behavior. Promoting selfmanagement is one of the key factors in controlling diabetes (3).

Self-management amongst adolescents is multidimensional and should include activities that youths and their parents can execute to care for the disease as well as collaboration with health care providers that assist them toward accepting full responsibility for managing their illness (4). Self-management training can help youngsters with diabetes to gain more independence, which enables them to learn that managing diabetes is to prevent its critical and chronic complications as well as glycemic control (5).

Furthermore, research has shown that the rate of self-management in adolescents with diabetes is much lower than in adults, consequently, adolescents face more complications than adults (6).

Diabetes self-management training is an integral part of its management and should be thought to all diabetes patients. Several studies have examined different training modalities to promote self-management for tackling diabetes, including; in-person training, text messaging (7), video(8), cellphone applications (2), etc. However, different results were achieved, and what is evident, is that different educational methods are not equally effective and it is necessary to evaluate their effects.

On the other hand, new educational modalities have paved the way to develop new teaching methods, using new technologies. Amongst them, digital storytelling seems to be an effective method to train adolescents. This modality can provide a powerful structure to organize and present data to its audience, regardless of the limitations caused by the learners' age, education, or learning level (9). In contrast to the traditional modalities, the storytelling approach incorporates memory-enhancing features, such as the story characters. The audience can search for these characters in his mind or even tries to associate with them. These factors can make the topic closer to the audience's mindset and the sequence of the story can help them to recall the storylines, and make the underlying educational concepts engraved in their long-term memory (10). Consciousness and motivation stimulate attention, which in turn results in enhanced active learning and understanding of the subject. The audience's level of awareness in the traditional classes quickly declines after 10 minutes, but in the storytelling method, the audience usually remains conscious and motivated (11), resulting in much better learning and 
understanding of the topic (12). Storytelling is an approach that enables afflicted people with diseases, such as diabetes to better understand their condition and find the right self-management strategies. Storytelling can combine learning by improving coping skills and ultimately motivate the patients to change their lifestyle (13).

Digital storytelling is a technology-based method, where the appropriate integration of a story with multimedia capabilities (text, audio, image, animation, and film) enables a simpler, wider, and more engaging transfer of educational concepts to facilitates active learning (10). Today, this method is widely used for transferring concepts to adolescences. Several studies were conducted on the effectiveness of this method, including the ones on the effects of digital storytelling on the academic achievements of young people (12), anxiety in patients undergoing cardiac surgery(13), adolescents' social intelligence(10), anxiousness and coping strategies in children with cancer (14); in addition to social skills amongst children by improving the sensory and cognitive awareness in autistic young people(11).

Although digital storytelling is a useful education tool for adolescents, this issue has received little attention in the area of selfmanagement training for adolescents with diabetes. Given that in this context no research has been carried out at Shiraz University of Medical Sciences; hence, the current research was performed to investigate the effects of digital storytelling on adolescents with TID and their self-management behaviors.

\section{Methods}

\section{Design}

The present study was a two-arm, parallel design randomized controlled trial with equal group allocation. The study adheres to CONSORT 2010 guidelines (Additional file 1).

\section{Participants}

\section{Eligibility criteria for participants:}

Inclusion criteria were all adolescents with TID between the age of 12 and 18 who were using medication (insulin) and willing to participate in the study. The participants and their families were also expected to have a basic knowledge of working with computer and educational DVDs as well as the ability to communicate on the telephone. The patients with any known physical or mental disabilities (mental, physical, vision, or hearing problems), or the ones who took anti-anxiety or antidepressant medication or had participated in other educational classes or courses on diabetes within the last 6 months were excluded. All the patients who were unwilling to continue their participation in this study were also excluded.

\section{Setting}

The study population included adolescents with TID who attended diabetes clinics affiliated with Shiraz University of Medical Sciences from July 2018 till September 2019.

\section{Intervention}

The intervention group received asynchronous Diabetes self-management training, using digital storytelling via a DVD; in addition to the routine training. The digital content in this study is a training DVD called "Diabetes and Bumblebee" designed and employed by the content development team in Virtual School of Shiraz University of Medical Sciences including an instructional designer, a pediatric endocrinologist, and one animation designer based on the nine-steps model of content development (15). It features 35 minutes of animation that provides adolescents with a brief description of the disease, its symptoms, and complications, treatment methods, the type of insulin, how to preserve insulin, the importance of nutrition and exercise in treating diabetes as well as efficient communication and collaboration with parents as well as health care providers. Exciting and interactive animations were used to depict the daily life of a youngster with diabetes.

The main cartoon character is called "Bumblebee", who explains the necessary points in a very simple and tangible language. The adolescent in our story shares his questions and has discussions about diabetes with his friend "Bumblebee". The "Bumblebee" also teaches him what youth with diabetes needs to know through storytelling. For example, an adolescent is shown how to inject insulin or where to do the injection (Fig. 1).

In addition, the participants receive regular phone calls (every two weeks) for following up on the intervention and to ask their questions. 
On the other hand, the control group received routine group training, including in-person training on how to inject insulin, how to measure blood glucose with a glucometer as well as diet and physical exercise. At the end of the training, all the participants in both groups were provided with an educational pamphlet. It should be noted that at the end of the research, the "Bumblebee" training DVD was given to the control group as well.

\section{Outcomes}

The primary outcome of the present study was to assess the Self-Management behavior at baseline and three months after interventions in both groups (intervention and control). The Self-Management behavior was evaluated according to the Self-Management of TID amongst adolescence, using (SMOD-A) questionnaire. The Persian version of the SMOD-A was used to check self-management behaviors in adolescents with TID. This version is a translation of the original self-management questionnaire by Schilling et al. (16), which includes 48 items in 5 domains; Cooperation with parents (the extent of parental involvement in diabetes management- 10 items), Diabetes care activities (the extent to which the adolescents perform key diabetes management activities - 12 items), Diabetes ProblemSolving (the extent the adolescent following the diet and knows the amount of HbA1c-8 items), Diabetes Communication (how often does the adolescent communicate with parents, health care team, and friends about their diabetes - 12 items), and Goal in Diabetes (more independent management of diabetes, prevention of uncontrolled blood glucose complications, participation in normal social activities with friends- 6 items). Each item is scored on a 4-point Likert scale ranging from 0 (never) to 3 (always) (17). Schilling et al. reported excellent content validity for this questionnaire $(0.89)$ and acceptable reliability of its subscales $(a=0.71-0.85)$. Alaei Karahroody et al [16] also reported acceptable content validity (0.98) and test-retest reliability for the Persian version of this questionnaire (0.73). Higher scores are associated with better self-management behaviors. The Sum of the score was 0.144 . Good self-management is shown by a higher than $70 \%$ total score. The participants had to spend 20 minutes to fill the questionnaire.

The secondary outcome was to assess the levels of $\mathrm{HbA1c}$ at baseline and three months after interventions in both groups (intervention and control). $\mathrm{HbA} 1 \mathrm{C}$ was used to determine the average level of blood glucose. Glycosylated hemoglobin is a biological indicator for selfmanagement in diabetes and is considered as the basis for treatment plans for patients with diabetes. For people without diabetes, the normal range for the $\mathrm{Hb} A 1 \mathrm{c}$ level is between 4 to $5.6 \%$ and in diabetic patients, the level is $6.5 \%$ and. higher (6). In this study, blood sampling and blood tests were conducted in the laboratory of a clinic at the research site. This process was supervised by one of the laboratory staff with sufficient knowledge and skills in this field.

\section{Sample size}

Based on the results of a pilot study we had conducted before the main study, the final sample size was determined. Assuming type I error $=0.05$, power $=0.8$, and the following equation, the sample size was determined at 33 patients in each group. Including the 30 patients from the pilot study (15 in each group), we selected 18 other patients in each group to reach the required sample size. This calculation $^{Z_{1-\frac{\alpha}{2}}}$ is considered 1.96 .

$$
n=\frac{\left(Z_{1-\frac{\alpha}{2}}+Z_{1-\beta}\right)^{2}\left(S_{1}^{2}+S_{2}^{2}\right)}{\left(\mu_{1}-\mu_{2}\right)^{2}}
$$

\section{Randomization}

The eligible Participants were randomly assigned to the intervention and control groups based on permuted block randomization. Since the total sample size was 66 (33 in each group), the block size was 6 and the number of blocks was 11. We used random allocation software to generate the list of randomization. The samples were blinded to intervention and control groups. The randomization and blinding were conducted by an assistant researcher who was not involved in the research protocol.

\section{Statistical methods}

The demographic characteristics of the participants are represented using descriptive statistics, i.e., mean \pm standard deviation, and frequency (percentage) for quantitative and qualitative variables, respectively. These characteristics were compared between the two groups, using the independent samples t-test and Chi-square test for numerical and categorical variables, respectively. Furthermore, in each group, paired sample t-test was used to compare the mean scores of self-management and HbA1c before and after the study. For comparing the mean scores of self-management and $\mathrm{HbA} 1 \mathrm{c}$ between the groups, independent samples t-test was applied. P-value $<0.05$ was considered to be statistically significant. The SPSS Version 15 was used to compute the descriptive statistics and the statistical tests.

\section{Results}


The 66 recruited individuals were recruited through convenience sampling, and eligible participants were randomized, using random allocation software. The participants were blinded into two "parallel" groups; intervention (digital storytelling) and control (conventional intervention) groups (Fig. 2).

The study lasted between July 2018 and September 2019. All the randomized patients completed the trial and the follow-up assessment. Participants' demographic characteristics are shown in Table 1.

Table 1. Participants' demographic data in digital storytelling and control groups

\begin{tabular}{|c|c|c|c|}
\hline \multirow[t]{2}{*}{ Variables } & Digital storytelling & Control & P-value \\
\hline & Mean \pm SD & \multicolumn{2}{|l|}{ Mean \pm SD } \\
\hline Age & $11.66 \pm 3.67$ & $13.42 \pm 3.21$ & $0.043^{*}$ \\
\hline Gender & $N(\%)$ & \multicolumn{2}{|l|}{$\mathrm{N}(\%)$} \\
\hline Girls & 19(57.6) & $22(66.7)$ & \multirow{2}{*}{$0.447^{9}$} \\
\hline Boys & $14(42.4)$ & 11(33.3) & \\
\hline \multicolumn{4}{|c|}{ Elapsed time since diagnosis of type 1 diabetes } \\
\hline Less than 1 year & 10(30.3) & $6(18.2)$ & \multirow[t]{2}{*}{$0.251^{9}$} \\
\hline More than 1 year & $23(69.7)$ & $27(81.8)$ & \\
\hline \multicolumn{4}{|c|}{ Mother's Educational level } \\
\hline Under diploma & 16(48.5) & 19(57.6) & \multirow[t]{2}{*}{$0.459^{9}$} \\
\hline Diploma and above & $17(51.5)$ & $14(42.4)$ & \\
\hline \multicolumn{4}{|c|}{ Father's Educational level } \\
\hline Under diploma & 18(54.5) & 15(39.4) & \multirow[t]{2}{*}{$0.218^{4}$} \\
\hline Diploma and above & 13(45.5) & $20(60.6)$ & \\
\hline \multicolumn{4}{|c|}{ *: P-value based on independent sample t-test } \\
\hline \multicolumn{4}{|c|}{ q:P-value based on Chi-square test } \\
\hline
\end{tabular}

As shown above, the mean age of individuals in the control group was significantly higher compared to the ones in the digital storytelling group. However, gender, time of diagnosis, parents' education level did not differ significantly between the groups.

The mean score of each subscale of the self-management questionnaire as well as $\mathrm{HbA} 1 \mathrm{c}$ before and after intervention in the intervention and control groups are shown in Table 2.

Our findings revealed that there was no significant difference between digital storytelling and control groups in terms of selfmanagement scores in all domains and total sores along with HbA1c (the column P-value ${ }^{b}$ ) before the study. Moreover, in the digital storytelling group, the mean scores of Collaboration with parents increased significantly from $23.78 \pm 5.17$ to $26.06 \pm 5.43$ after the intervention ( $p$-value $<0.001$ ). A significant increase was also observed in the mean score of the Diabetes communication dimension (from $24.57 \pm 9.22$ before the intervention to $26.69 \pm 9.06$ after the intervention, $p$-value $=0.015$ ). There was a two-unit increase in the mean score of the Goal dimension ( $p$-value $<0.001$ ). In addition, the total score of self-management raised significantly from $92.87 \pm$ 21.28 before the intervention to $100.12 \pm 18.2$ after the intervention ( $p$-value $=0.005$ ). Since there were no significant differences between the groups before the study, we compare the after-intervention scores by independent samples t-test. Our results showed that the mean score of Collaboration with parents was significantly higher in the digital storytelling group as opposed to the control group (26.06 \pm 5.43 vs. $22.36 \pm 6.05$, $p$-value $=0.011$ ). This implied that our intervention had a beneficial effect on this subscale of self-management.

Table 3 presents the Pearson correlation between age and self-management scores along with $\mathrm{HbA} 1 \mathrm{c}$ after the intervention in the digital storytelling group. 
Table 2: Within- and between-group comparison of each dimension of self-management scores before and after the intervention

\begin{tabular}{|c|c|c|c|c|c|c|c|c|c|}
\hline \multirow[t]{3}{*}{ Variables } & \multicolumn{3}{|c|}{ Digital storytelling } & \multicolumn{6}{|l|}{ Control } \\
\hline & \multirow{2}{*}{$\begin{array}{l}\text { Before } \\
\text { Mean } \pm \text { SD }\end{array}$} & \multicolumn{2}{|l|}{ After } & \multirow[t]{2}{*}{ Before } & \multicolumn{2}{|l|}{ After } & \multicolumn{3}{|c|}{$\begin{array}{l}\text { Between-group } \\
\text { comparison }\end{array}$} \\
\hline & & Mean \pm SD & $\begin{array}{l}\mathrm{p}- \\
\text { value }^{\mathrm{w}}\end{array}$ & & Mean $\pm S D$ & $\begin{array}{l}\mathrm{p}- \\
\text { value }^{\mathrm{w}}\end{array}$ & $\begin{array}{l}\mathrm{p}- \\
\text { value }^{\mathrm{b}}\end{array}$ & $\begin{array}{l}\mathrm{p}- \\
\text { value }^{\mathrm{a}}\end{array}$ & Cohens'd* \\
\hline $\begin{array}{l}\text { Collaboration } \\
\text { with parents }\end{array}$ & $23.78 \pm 5.17$ & $26.06 \pm 5.43$ & $<0.001$ & $22.69 \pm 5.81$ & $22.36 \pm 6.05$ & 0.620 & 0.423 & 0.011 & 0.64 \\
\hline $\begin{array}{l}\text { Diabetes care } \\
\text { activities }\end{array}$ & $17.15 \pm 6.75$ & $16.78 \pm 4.42$ & 0.739 & $17.78 \pm 5.67$ & $18.00 \pm 4.98$ & 0.789 & 0.680 & 0.300 & 0.26 \\
\hline $\begin{array}{l}\text { Diabetes } \\
\text { problem- } \\
\text { solving }\end{array}$ & $14.15 \pm 4.71$ & $15.36 \pm 5.07$ & 0.155 & $14.93 \pm 3.52$ & $15.12 \pm 3.07$ & 0.746 & 0.445 & 0.815 & 0.06 \\
\hline $\begin{array}{l}\text { Diabetes } \\
\text { communication }\end{array}$ & $24.57 \pm 9.22$ & $26.69 \pm 9.06$ & 0.015 & $3.93 \pm 6.61$ & $24.54 \pm 7.59$ & 0.464 & 0.749 & 0.300 & 0.26 \\
\hline Goals & $13.21 \pm 3.37$ & $15.21 \pm 3.07$ & $<0.001$ & $14.78 \pm 3.06$ & $15.33 \pm 2.21$ & 0.241 & 0.051 & 0.855 & 0.04 \\
\hline Total & $92.87 \pm 21.28$ & $100.12 \pm 18.2$ & 0.005 & $94.15 \pm 18.02$ & $95.36 \pm 17.05$ & 0.574 & 0.794 & 0.278 & 0.27 \\
\hline $\mathrm{HbA1c}$ & $8.76 \pm 2.14$ & $8.75 \pm 1.97$ & 0.991 & $9.97 \pm 2.03$ & $9.20 \pm 2.31$ & 0.166 & 0.030 & 0.474 & 0.21 \\
\hline
\end{tabular}

p-value ${ }^{\mathrm{w}}$ : within-group comparison in each interventional and control group

p-value ${ }^{\text {b: }}$ between-group comparison before the intervention

p-value ${ }^{a}$ : between-group comparison after the intervention

*: effect size

Pearson correlation coefficient was used to compare self- management behavior scores and demographic variables, such as age, gender, elapsed time since diagnosis of type 1 diabetes, paternal education level, and maternal education level.

Table 3

Correlation coefficient between age and post-self-management scores along with post HbA1c in the digital storytelling group

\begin{tabular}{|llllllll|}
\hline $\begin{array}{l}\text { Collaboration } \\
\text { with parents }\end{array}$ & $\begin{array}{l}\text { Diabetes care } \\
\text { activities }\end{array}$ & $\begin{array}{l}\text { Diabetes } \\
\text { problem-solving }\end{array}$ & $\begin{array}{l}\text { Diabetes } \\
\text { communication }\end{array}$ & Goals & Total & HbA1c \\
\hline Age & $-0.347(0.048)$ & $-0.208(0.246)$ & $0.082(0.650)$ & $-0.005(0.978)$ & $0.125(0.488)$ & $-0.112(0.533)$ & $0.156(0.386)$ \\
\hline
\end{tabular}

It can be observed that there was only a significant relationship between age and post Collaboration with parents scores; the increment of age led to the reduction of post Collaboration with parents scores ( $r=-0.347$, p-value $=0.048$ ). It should be noted that the relationship of the other baseline characteristics, such as mother and father education levels and adolescents' gender were also investigated, but no significant relation was observed. The results are not shown here due to space limitations.

It should be noted that no harm or unintended effects were observed in either group.

\section{Discussion}

The results of the present clinical trial revealed that self-management training through digital storytelling led to improvement in selfmanagement behaviors amongst adolescents with TID compared to the control group. There are several reasons why digital storytelling can lead to superior performance. In comparison to the conventional approach, storytelling provides a more exciting and enjoyable experience for youths, given their general interest in stories (10). Thus, these advantages might result in greater effectiveness of training through the storytelling method. 
On the other hand, patients in the control group underwent only one 2-hour group educational session and a pamphlet at the end of the class. After this training, the teenagers did not receive any training until their next visit. Many studies have been conducted on the effectiveness of face-to-face training amongst youth patients. Most of which emphasize that lecture-based training can have little effect on the level of long-term learning and the quality of self-management in young patients compared to active and attractive learning methods, such as digital storytelling. This method serves as one of the most fundamental methods to subliminally transfer concepts to audiences, especially adolescents [7]. Other research in this area also emphasizes the fact that training through digital storytelling method can have an influential effect compared to conventional methods by improving patients' healthy behaviors (18), lowering blood pressure (13), managing diabetes mellitus(19), and psychological wellbeing (12).

In addition, we used the asynchronous method (DVD) to promote learning in our research. This method allows patients to interact with the story and its educational message and allows them to learn at their desired time, place, and pace (20). This finding is also in line with the results revealing the effects of asynchronous learning on knowledge, activation, self-management, and self-efficacy in patients with diabetes (21). Therefore, asynchronous digital storytelling allows patients to learn at their own desired time, place, and learning pace to reach mastery in learning and self-management behaviors.

Moreover, the results showed that the score for self-management in the digital storytelling group significantly increased in the collaboration with parents, diabetes communication, and goals dimensions. These upsurges revealed that the adolescents were able to set more accurate self-management goals. Also, the relationship between adolescents and parents, healthcare team, and friends had improved. Furthermore, they were able to create a proper balance in the dividing caring responsibilities between parents and themselves, which ultimately led to more independence [19].

Additionally, the results of this study showed that there was a significant reverse relationship between the age of the adolescents and collaboration with parent's scores after digital storytelling, while this relationship was not significant in the control group. The research also showed that as teenagers grow older, they become more independent for self-management through digital storytelling methods. Thus, cooperation and dividing responsibilities in self-management go gradually towards independence as the adolescent gets older (5).

We also examined other factors that could potentially affect the results of our study. The results showed that parents' education level had no significant relationship with the rate of change in self-management behaviors in adolescents with TID in any of the study groups. Nowadays, the ever-growing activities of mass media and social networks have risen parents' awareness with respect to various diseases (regardless of their level of education); hence, their compassion and rapid response have also increased (22). This development can be considered as the reason for the lack of any significant relationship between parental education and the rates of change in selfmanagement behaviors in adolescents with TID.

The results also showed that in both groups there was no significant relationship between the adolescents 'gender and the rates of change in their self-management behaviors. The results of a study by Vasli \& Eshghbaz [23] similarly showed that there was no significant relationship between gender and self-management behavior in 7-14-year-old teenagers with TID. However, Martinez et al. [24] reported that self-management behavior in female adolescents with diabetes was better than in males. Of course, one should not ignore the role of context and environment in adolescent's self-care behaviors.

Moreover, the results of this study suggested that no significant relationship was observed concerning the rate of change in the level of $\mathrm{HbA1c}$ in neither of the groups. Although Azizi et al. (21) and colleagues showed that self-management training with a 3-month follow-up through mobile services significantly reduced $\mathrm{HbA} 1 \mathrm{c}$ in adolescents with TID. This is in contrast to the results of the present study and highlights the importance of long-term follow-up.

This study had several limitations. First, it was performed in only one center; hence, it has to be executed on a wider scale for its results to be applicable as general. Furthermore, only short-term effects were investigated. So, the results cannot be generalized to all adolescents with TID. Therefore, long-term follow-up is warranted.

For future research, it is recommended that diabetes self-management training through digital storytelling be administered for a much longer time and with a larger sample size to achieve a more accurate measurement of the level of HA1c and self-management behaviors in patients before and after the training course.

\section{Conclusion}


Current study results prove that diabetes self-management training through digital storytelling can bring about a significant improvement in adolescences with TID on self-management behaviors. However, there was no difference between the level of HbA1c in adolescence before and after the training.

\section{Declarations}

\section{- Ethics approval and consent to participate}

The present study was approved by the local ethics committee of Shiraz University of Medical Sciences (decree code: IR.SUMS.REC.1398.244). Following ethical principles, the researchers explained the aims, methods, and conditions of the study to the participating adolescents and their parents, and written informed consent was obtained from them. Participants were assured of the confidentiality of their data, and that only general statistics would be presented.

\section{- Consent for publication}

Not applicable

\section{- Availability of data and materials}

The data that support the findings of this study are available from the corresponding author on request.

\section{- Competing interests}

The authors declare that they have no competing interests.

\section{- Funding}

The authors would like to thank the Vice-chancellor of Research at Shiraz University of Medical Sciences, Shiraz, Iran, for their financial support (grants No. 1398.244).

\section{- Authors' contributions}

NZ devised the study concept, designed the study, supervised the intervention, data collection, analysis, participated in the coordination of the research, and critically revised the manuscript. M OS ran the study intervention, data collection, Writing- Original draft preparation. ZB analysis, and critically revised the manuscript. MM Reviewing and Edit. All authors have read and approved the content of the manuscript.

\section{- Acknowledgments}

This article was the result of a master's thesis research project at Shiraz University of Medical Sciences (SUMS). We are grateful to the research counselor of SUMS for supporting this study, the Clinical Research Development Centre for the statistical analysis, and the Virtual School of SUMS for developing electronic content. The authors wish to thank Prof. Zohreh Karamizadeh for cooperation in designing the storytelling content, and Mr. H. Argasi at HR Publication for his invaluable assistance in editing this manuscript. We also wish to thank the adolescents and their parents for their sincere help and cooperation in conducting the present study.

\section{References}

1. Radcliff Z, Weaver P, Chen R, Streisand R, Holmes C. The Role of Authoritative Parenting in Adolescent Type 1 Diabetes Management. J Pediatr Psychol. 2018 Mar 1;43(2):185-94.

2. Jahanbakhsh M, Ehteshami A, Afkhami S. Developing “Aryan:” Diabetes self-care mobile application. Int J Prev Med. $2019 ; 10(1): 59$.

3. Shabibi P, Abedzadeh Zavareh MS, Sayehmiri K, Qorbani M, Safari O, Rastegarimehr B, et al. Effect of educational intervention based on the Health Belief Model on promoting self-care behaviors of type-2 diabetes patients. Electron Physician. 2017 Dec 25;9(12):5960-8.

4. Aminuddin HB, Jiao N, Jiang Y, Hong J, Wang W. Effectiveness of smartphone-based self-management interventions on self-efficacy, self-care activities, health-related quality of life and clinical outcomes in patients with type 2 diabetes: A systematic review and metaanalysis. International Journal of Nursing Studies. Elsevier Ltd; 2019. p. 103286. 
5. Jackson CC, Albanese-O'Neill A. Supporting the Student's Graduated Independence in Diabetes Care. NASN Sch Nurse [Internet]. 2016 Jul 3 [cited 2020 Apr 28];31(4):202-4. Available from: http://journals.sagepub.com/doi/10.1177/1942602X16651749

6. Samuelsson U, Anderzén J, Gudbjörnsdottir S, Steineck I, Åkesson K, Hanberger L. Teenage girls with type 1 diabetes have poorer metabolic control than boys and face more complications in early adulthood. J Diabetes Complications. 2016 Jul 1;30(5):917-22.

7. Samimi Z, Talakoub S, Ghazavi Z. Effect of telephone follow-up by nurses on self-care in children with diabetes. Iran J Nurs Midwifery Res. 2018;23(1):26-30.

8. Abrar EA, Yusuf S, Sjattar EL, Rachmawaty R. Development and evaluation educational videos of diabetic foot care in traditional languages to enhance knowledge of patients diagnosed with diabetes and risk for diabetic foot ulcers. Prim Care Diabetes. 2020 Apr 1;14(2):104-10.

9. Swift A, Etherton J, Twycross A. Keeping the patient front and central: The role of storytelling. Vol. 22, Evidence-Based Nursing. BMJ Publishing Group; 2019. p. 31-2.

10. Lisenbee PS, Ford CM. Engaging Students in Traditional and Digital Storytelling to Make Connections Between Pedagogy and Children's Experiences. Early Child Educ J. 2018 Jan 1;46(1):129-39.

11. Papacharissi Z. Affective publics and structures of storytelling: sentiment, events and mediality. Inf Commun Soc. 2016 Mar 3;19(3):307-24.

12. Kory Westlund JM, Jeong S, Park HW, Ronfard S, Adhikari A, Harris PL, et al. Flat vs. Expressive Storytelling: Young Children's Learning and Retention of a Social Robot's Narrative. Front Hum Neurosci [Internet]. 2017 Jun 7 [cited 2020 Apr 28];11:295. Available from: http://journal.frontiersin.org/article/10.3389/fnhum.2017.00295/full

13. Moghimian M, Akbari M, Moghaddasi J, Niknajad R. Effect of Digital Storytelling on Anxiety in Patients Who Are Candidates for Open-Heart Surgery. J Cardiovasc Nurs [Internet]. 2019 May 1 [cited 2020 Apr 28];34(3):231-5. Available from: http://insights.ovid.com/crossref?an=00005082-201905000-00008

14. Wilson DK, Hutson SP, Wyatt TH. Exploring the Role of Digital Storytelling in Pediatric Oncology Patients' Perspectives Regarding Diagnosis. SAGE Open [Internet]. 2015 Mar 20 [cited 2020 Sep 11];5(1):215824401557209. Available from: http://journals.sagepub.com/doi/10.1177/2158244015572099

15. Mehrabi M. 78 Mehrabi M. Setting up the Structure and Process for E-Content Development. Interdiscip J Virtual Learn Med Sci. 2019;10(4):78-80.

16. Karahroudy FA, Shahboulaghi FM, Hosseini MA, Rassouli M, Biglarian A. Translation and psychometric properties of the Persian version of self-management of type 1 diabetes for adolescents. J Pediatr Endocrinol Metab. 2016 Jul 1;29(7):761-7.

17. Guo J, Yang J, Wiley J, Ou X, Zhou Z, Whittemore R. Perceived stress and self-efficacy are associated with diabetes selfmanagement among adolescents with type 1 diabetes: A moderated mediation analysis. J Adv Nurs [Internet]. 2019 Dec 6 [cited 2020 Sep 11];75(12):3544-53. Available from: https://onlinelibrary.wiley.com/doi/abs/10.1111/jan.14179

18. Fiddian-Green A, Kim S, Gubrium AC, Larkey LK, Peterson JC. Restor(y)ing Health: A Conceptual Model of the Effects of Digital Storytelling. Health Promot Pract [Internet]. 2019 Jul 8 [cited 2020 Apr 28];20(4):502-12. Available from: http://journals.sagepub.com/doi/10.1177/1524839918825130

19. Gucciardi E, Richardson A, Aresta S, Karam G, Sidani S, Beanlands H, et al. Storytelling to Support Disease Self-Management by Adults With Type 2 Diabetes. Can J Diabetes. 2019 Jun 1;43(4):271-277.e1.

20. Zhang Y, Clavera I, Tsai B, Abbeel P. Asynchronous Methods for Model-Based Reinforcement Learning. 2019 Oct 28 [cited 2020 Apr 28]; Available from: http://arxiv.org/abs/1910.12453

21. Wong EM, Lam GY. Can E-Health Support Programme Improve Self-Management for Diabetes Patients in the Community? J Community Public Heal Nurs. 2016;2(1).

22. Vaughn LM, McLinden D, Jacquez F, Crosby L, Slater S, Mitchell M. Understanding the social networks of parents of children with sickle cell disease. J Health Care Poor Underserved. 2011;22(3):1014-29.

\section{Figures}




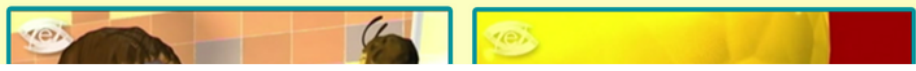

\section{Figure 1}

Screenshots of the digital storytelling DVD developed by the virtual school 


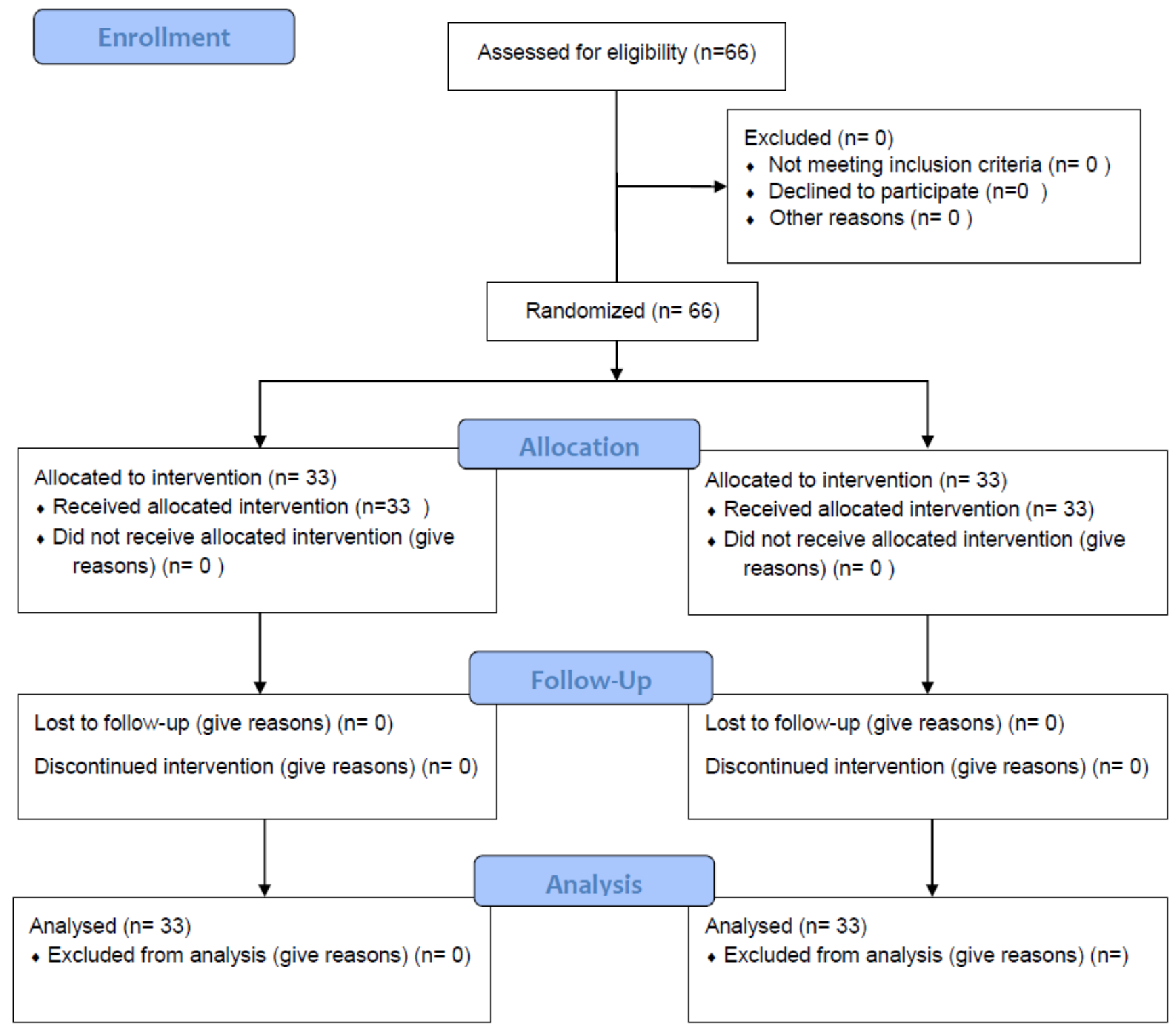

\section{Figure 2}

The patient's recruitment flow diagram.

\section{Supplementary Files}

This is a list of supplementary files associated with this preprint. Click to download.

- additionalfile1CONSORT2010Checklist.doc 